\title{
Tuberculosis of the Female Breast and Reproductive Organs: A Diagnostic Dilemma
}

Modupeola O Samaila ${ }^{1 *}$, Adebiyi G adesiyun ${ }^{2}$, Turaki T Mohammed ${ }^{3}$, Sunday A Adewuyi ${ }^{3}$ and Bello Usman ${ }^{1}$

${ }^{1}$ Department of Pathology, Ahmadu Bello University Teaching Hospital Shika, Zaria, Nigeria

${ }^{2}$ Department of Obstetrics \& Gynaecology, Ahmadu Bello University Teaching Hospital Shika, Zaria, Nigeria

${ }^{3}$ Department of Medicine, Ahmadu Bello University Teaching Hospital Shika, Zaria, Nigeria

\begin{abstract}
Background: Tuberculosis is prevalent in developing countries and extra-pulmonary involvement is now a frequent manifestation. However, involvement of the breast and reproductive organs in females is a cause of diagnostic confusion due to the non- specific nature of presenting symptoms which may simulate malignant disease processes.
\end{abstract}

Materials and methods: All females with histological confirmation of tuberculosis involving the breast and reproductive organs were analyzed over a 16 year period. Tissue biopsies were fixed in formalin, processed in paraffin and stained with haematoxylin \& eosin and Ziehl Neelsen stain to identify the acid fast bacilli of mycobacterium tuberculosis.

Results: 28 females are presented and their ages ranged from 14 to 52 years with a mean age of 29.3. Presenting symptoms were varied and included abdominal/pelvic pain, abdominal swelling, post coital bleeding, vaginal bleeding and discharge, amenorrhoea and infertility while four females presented with breast mass and pain. Duration of symptoms was from one month to 5 years. Clinical diagnosis included dermoid cyst, tubo-ovarian abscess, leaking ectopic gestation, malignant ovarian tumour, fibroadenoma and breast cancer. Eighteen of the females had laparotomy, four had endometrial curettage, another four had excision biopsy/lumpectomy and two had cervical punch biopsy. Only the four females with breast lesions had fine needle aspiration biopsy prior to tissue biopsy. Also, one female was HIV positive and on anti-retroviral drugs. Microscopy of tissue biopsies from the breast, ovary, fallopian tubes, endometrium and cervix revealed granulomata, multinucleated langhan type giant cells and extensive caesation.

Conclusion: Tuberculosis may mimic malignant lesions of the breast, ovary and cervix due to the absence of specific diagnostic symptoms and should be a differential diagnosis in breast and gynaecological diseases in reproductive age females. In resource limited setting, early diagnosis by fine needle aspiration technique and tissue histology may reduce attendant morbidity, irreversible sterility and also prevent unnecessary surgery in patients.

Keywords: Tuberculosis; Breast; Ovary; Cancer; Infertility; Reproductive age

\section{Introduction}

Tuberculosis affects one third of the world's population and Africa contributes $3 \%$ to $4 \%$ cases annually to the global epidemic [1-4]. It is primarily a pulmonary disease treated by multidrug therapy. The advent of multidrug resistant strains and HIV infection is steadily increasing its extra-pulmonary manifestation in developing countries and in predominant migrant populations in developed countries [5-7].

The female breast is structurally complex and undergoes varying morphologic changes from adolescence to menopause [8,9]. These changes are subject to hormonal control which may result in varying pathologic conditions ranging from benign fibrocystic changes to cancer. However, injection by tuberculosis is uncommon in the breast due to the resistance of breast tissue to the tubercule bacillus survival and multiplication [10-14]. Genital tuberculosis, though uncommon, occurs during the reproductive years and results from haematogenous spread involving the fallopian tubes and extends to the endometrium, cervix uteri and ovaries [15]. The annual incidence of genital tuberculosis is estimated at 0.036 per 100,000 women of child bearing age while its incidence in the breast ranges from $0.1 \%$ to $3.59 \%$ and includes lactating females [12,13,16-18].

There is no specific symptom or clinical presentation associated with tuberculosis of the breast and genital organs and thus a source of diagnostic difficulty from neoplastic gynaecological and breast diseases in reproductive age females.

\section{Materials and Methods}

Twenty eight female patients with histological diagnosis of tuberculosis involving the breast and reproductive organs were studied in the Department of Pathology, Ahmadu Bello University Teaching Hospital over a 16 years period (January 1997 to December 2012). Tissue biopsies of these patients were fixed in 10\% formalin and processed in paraffin wax. Histology slides stained with Haematoxylin and Eosin (H\&E) were viewed. Ziehl Neelsen stain was used to demonstrate the presence of acid fast bacilli (AFB) of mycobacterium tuberculosis. Clinical information and bio-data of patients were extracted from case files.

\section{Results}

Two hundred and forty seven patients (247) had histological diagnosis of tuberculosis during the study period. There were 133 males

*Corresponding author: Modupeola O Samaila, Department of Pathology, Ahmadu Bello University Teaching Hospital Shika, Zaria, Nigeria, Tel: +234 8035891007; E-mail: mamak97@yahoo.com

Received July 30, 2013; Accepted September 02, 2013; Published September 05, 2013

Citation: Samaila MO, adesiyun AG, Mohammed TT, Adewuyi SA, Usman B (2013) Tuberculosis of the Female Breast and Reproductive Organs: A Diagnostic Dilemma. J Trop Dis 1: 116. doi:10.4172/2329-891X.1000116

Copyright: (c) 2013 Samaila MO, et al. This is an open-access article distributed under the terms of the Creative Commons Attribution License, which permits unrestricted use, distribution, and reproduction in any medium, provided the original author and source are credited. 


\begin{tabular}{|c|c|c|c|c|c|}
\hline S/No & $\begin{array}{l}\text { Age } \\
\text { (years) }\end{array}$ & Symptoms / Clinical presentation & $\begin{array}{l}\text { Duration of symptoms } \\
\text { (months) }\end{array}$ & $\begin{array}{l}\text { Sites of tissue Specimen for } \\
\text { Histology }\end{array}$ & Clinical Diagnosis \\
\hline 1 & 33 & Vaginal bleeding, discharge & 7 & $\begin{array}{l}\text { Endometrium } \\
\text { Cervix }\end{array}$ & CIN 1 \\
\hline 2 & 35 & $\begin{array}{l}\text { Profuse vaginal discharge, ulcerated friable } \\
\text { cervix and vulva }\end{array}$ & 8 & Cervix u/vulva & Cancer cervix \\
\hline 3 & 30 & Vaginal bleeding following Amenorrhoea, & 4 & Endometrium & Product of conception \\
\hline 4 & 21 & Abdomino-pelvic swelling & 6 & Ovary & Serous ovarian cyst \\
\hline 5 & 25 & $\begin{array}{l}\text { Abdomino-pelvic swelling, weight loss, } \\
\text { amenorrhoea }\end{array}$ & 6 & Tube \& Ovary & Neoplastic ovarian tumour \\
\hline 6 & 20 & Vaginal discharge $\&$ bleeding & 4 & Cervix & Chronic PID \\
\hline 7 & 25 & Vaginal bleeding \& discharge, pelvic pain & 3 & Ovary & Tubo-ovarian abscess \\
\hline 8 & 28 & Abdomino-pelvic mass, weight loss & 6 & Ovary & Malignant ovarian cyst \\
\hline 9 & 28 & Amenorrhoea, vomiting, fever & 2 & Tube \& ovary & Leaking Ectopic gestation \\
\hline 10 & 19 & Amenorrhoea, fever, vomiting & 2 & Tube & Leaking ectopic gestation \\
\hline 11 & 17 & Abdomino-pelvic mass, pain, & 10 & Tube \& Ovary & Chronic Ectopic gestation \\
\hline 12 & 52 & $\begin{array}{l}\text { Abdomino-pelvic pain, Pelvic mass-22wks, } \\
\text { vaginal bleeding }\end{array}$ & 12 & Ovary, Tubes, Uterus & $\begin{array}{l}\text { Malignant ovarian tumour } \\
\text { stage IIIc }\end{array}$ \\
\hline 13 & 26 & Lower abdominal pains & 2 & Tube \& Ovary & PID, Oophritis \\
\hline 14 & 32 & Amenorrhoea & 60 & Endometrium & Secondary infertility \\
\hline 15 & 29 & Breast mass, peau d' orange, tenderness & 14 & Breast & Mastitis/Breast cancer \\
\hline 16 & 35 & Abdominal swelling, abnormal menstruation & 60 & Tube \& Ovary & Ovarian cyst \\
\hline 17 & 28 & Breast pain and lump & 4 & Breast & Fibroadenoma \\
\hline 18 & 17 & Abdominal swelling & 6.5 & Ovary & Dermoid cyst \\
\hline $19^{*}$ & 25 & Abdomino-pelvic swelling & 8 & Ovary & Tuberculous OOphritis \\
\hline 20 & 41 & Post coital bleeding & 60 & Cervix uteri & Cancer cervix \\
\hline 21 & 19 & Lower abdominal pain \& mass, vaginal discharge & 6 & Tubes \& ovaries & Malignant Ovarian tumour/ Disseminated TB \\
\hline $22^{\star *}$ & 42 & Weight loss, fever, breast mass, paeu d'orange & 6 & Breast & Breast cancer \\
\hline 23 & 14 & Amenorrhoea, abdominal swelling & 4- 12 & Ovary \& Left Tube & Ovarian mass/ Cold abscess \\
\hline 24 & 40 & Vaginal bleeding, abdominal swelling & 18 & $\begin{array}{l}\text { Uterus, tubes, ovaries \& } \\
\text { peritoneal seedlings }\end{array}$ & CIN-III/Ca cervix \\
\hline 25 & 45 & Lower abdominal mass, & 24 & ovary & Ovarian cyst \\
\hline 26 & 35 & $\begin{array}{l}\text { Fever, weight loss, breast lump, } 6 \text { months } \\
\text { pregnant }\end{array}$ & 12 & Breast & Breast cancer \\
\hline 27 & 38 & Post coital bleeding, prolonged menstruation & 24 & Endometrium & Cervicitis/Abnormal Uterine bleeding \\
\hline 28 & 22 & Lower abdominal swelling & 24 & Ovary & Ovarian Tumour \\
\hline
\end{tabular}

*Known Tuberculosis patient

** Defaulted Retroviral positive patient

Table 1: Clinical Details, Presentations and Diagnoses of Patients.

and 114 females. Of the females, 28 had tuberculosis involving the breast, fallopian tube, ovary, endometrium and cervix uteri. Their ages ranged from 14 to 52 years with a mean age of 29.3. They presented with varying histories of breast pain, breast lump, abdominal swelling/mass, abdominal/pelvic pain, vaginal bleeding/discharge, post coital bleeding, amenorrhoea, weight loss, vomiting and fever. One female presented due to secondary infertility and one was a known tuberculosis case who defaulted on treatment. Of the four women with breast masses, one was a known HIV infected patient on HAART and one was six months pregnant. The presenting symptoms durations for all the cases varied from one month to 5 years (Table 1 ).

Clinical examination showed ulcerated and friable cervix uteri with lesions extending to the vaginal vault and vulva in one patient, another had bilateral tubo-ovarian masses, while a pelvic mass of 22 weeks gestation size was demonstrable in one. Ill defined to circumscribed nodular breast lumps were seen in four cases and two had associated peau d' orange. The range of clinical diagnoses and differentials included dermoid cyst, tubo-ovarian abscess, leaking tubal gestation, pelvic inflammatory disease, malignant ovarian tumour, fibroadenoma, cervical intra-epithelial neoplasia, cervical cancer and breast cancer (Table 1).
Eighteen patients had a laparotomy for suspected ectopic gestation, tubo-ovarian abscess and ovarian tumour, four had endometrial curettage for incomplete abortion, cervicitis and infertility while another two had a cervical punch biopsy. All four with breast lesions had fine needle aspiration cytology and subsequent excision biopsy. Of the eighteen that had laparotomy, two had total abdominal hysterectomy with bilateral salpingo-oophorectomy for suspected advanced malignant ovarian tumour and high grade cervical intraepithelial neoplasia.

Tissue microscopy of biopsies from the breast, fallopian tubes, ovaries, endometrium and cervix uteri showed granulomata composed of epithelioid cells, lymphocytes, multinucleated langhan and foreign body giant cells and extensive areas of ceasation (Figures 1-3). Other areas from the respective tissues showed residual breast tissue and fibrocystic change in one breast, expanded tubal wall, ovarian stroma and ectocervical epithelium. Ziehl Neelsen stains revealed acid fast bacilli of mycobacterium tuberculosis. All the patients received standard anti tuberculous drugs without further surgical intervention. The female with secondary infertility was yet to achieve pregnancy. 


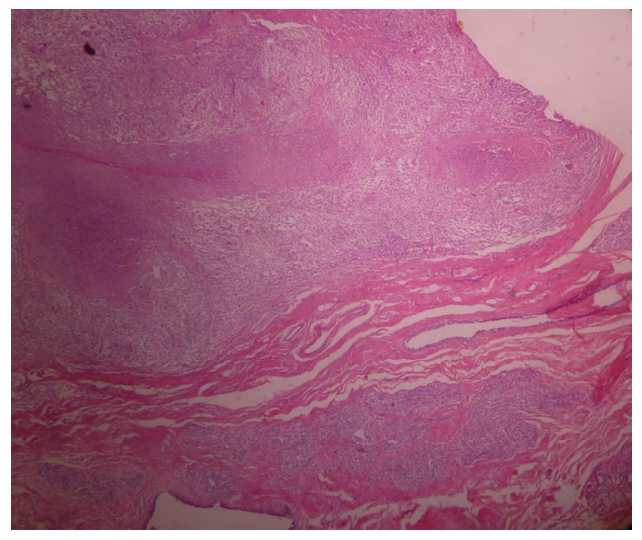

Figure 1: Breast Tissue showing granuloma, caesation and occasional acinus.

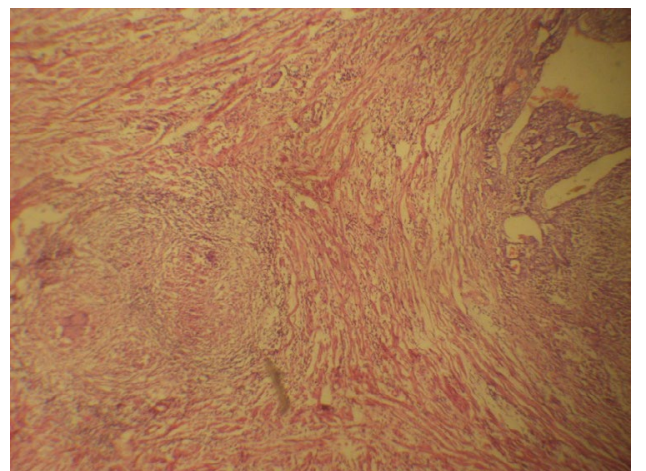

Figure 2: Expanded Tubal wall showing granuloma \& fimbriae.

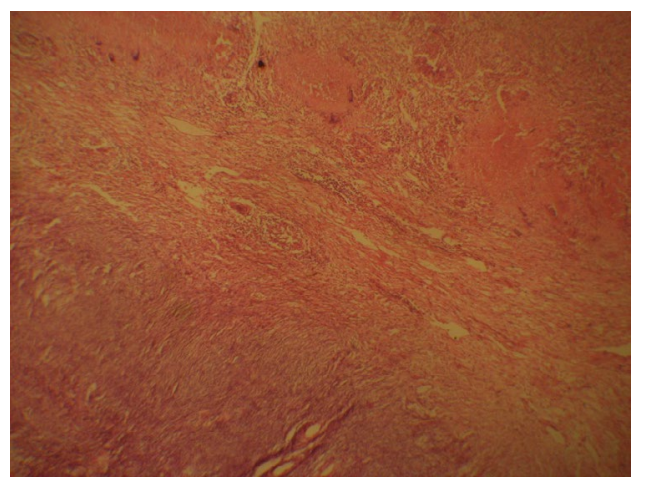

Figure 3: Residual ovarian stroma and granuloma.

\section{Discussion}

The resistance of the breast to tuberculosis infection is reduced during pregnancy and lactation due to increased blood flow and thus infection can be acquired through skin abrasions, ducts in the nipple or from a primary focus [19]. Presentation with peau dorange and breast lump or mass can mimic breast cancer which is the commonest malignancy amongst females in our setting and a leading cause of death in women in developing countries. We had four women with breast tuberculosis, one was pregnant and another was a known retroviral case. Several reports of pregnancy exacerbating breast cancer have also been documented in literature. It is noteworthy that the occurrence of breast lump during pregnancy may be tuberculosis as seen in our patient. HIV infection is also known to increase the propensity to tuberculosis in afflicted individuals [7,20,21].

The first case of tuberculous mastitis was described by Cooper [22] as "scrofulous swelling of the bosom" and McKeown and Wilkinson [23] first classified it into five pathological varieties of nodular, diffuse or disseminated, sclerosing, tuberculous mastitis obliterans and acute military tuberculous mastitis based on clinical manifestation. While, Tewari reclassified it into nodular, disseminated and abscess types [20]. The nodular variant is the commonest presentation in $60 \%$ of cases and thus may be misdiagnosed as a neoplastic lesion as also seen in our patients while, the abscess variant is often seen in young females and accounts for $30 \%$ of cases [20]. Diagnosis can be achieved with Fine Needle Aspiration Cytology (FNAC) though tissue biopsy is still advocated to differentiate from other causes of granulomatous diseases of the breast [24-26]. Granuloma centering round breast ducts and not lobules is diagnostic in tissue biopsy and the demonstration of acid fast bacilli is not mandatory [11].

Genital tuberculosis in females is prevalent during the reproductive years $[8,27,28]$. It is an uncommon manifestation of the disease and accounts for $0.7 \%-1 \%$ of gynaecologic admissions [29]. Over $90 \%$ of cases are diagnosed between 20-40 years [8]. The age range for our patients was from 14 years to 52 years with an average of 29.3 years. This range is expected because reproductive period is longer in our setting from early female marriages. Our finding is also comparable to similar studies $[27,28]$.

The clinical manifestation of tuberculosis in this group of patients is variable and non specific thus posing a diagnostic difficulty from inflammatory and neoplastic gynaecological diseases. However, presenting symptoms often include pelvic pain, swelling and infertility in majority of cases though infertile patients rarely have symptoms $[8,30,31]$. We had one case of secondary infertility in a thirty-two years old woman who was desirous of pregnancy. The incidence of tuberculosis in infertile patients ranges from $5 \%$ to $16.4 \%[8,28]$. In spite of adequate treatment with standard anti tuberculous drugs, many affected females like our patient will still not achieve pregnancy without other forms of medical interventions such as in vitro fertilization [32]. Other symptoms encountered in patients are abnormal uterine bleeding, amenorrhoea, pelvic swelling and vaginal discharge [33]. Fourteen (51.9\%) of our patients had menstrual irregularity with vaginal discharge. Weight loss, malaise and temperature rise are often associated with tuberculosis though, these symptoms are non specific and may also be attributable to genital infection [33].

The ovary and fallopian tube were the frequent sites in this study with 16 and 9 cases respectively while 9 females had both organs involved. Other studies reported the ovary and endometrium as prevalent sites $[27,33]$. Only four had endometrial affectation in our study while one female had extensive vulva involvement. Vulval tuberculosis is rare and accounts for $0.2 \%$ of cases [34]. Pathogenetically, tuberculosis spreads haematogenously from the fallopian tubes to the endometrium, ovaries and cervix uteri in decreasing frequency order $[8,28,30]$.

Breast and genital tuberculosis cannot be differentiated from the myriad of breast and gynaecological lesions such as fibroadenoma, fibrocystic changes, inflammatory diseases of the pelvis, ovarian tumours, uterine and breast malignancies on clinical features alone [30,33,35-37]. A combination of FNA for palpable masses, laparoscopy and tissue biopsy is the best approach to diagnosis in reproductive age women as well as a high index of suspicion especially in susceptible 
Citation: Samaila MO, adesiyun AG, Mohammed TT, Adewuyi SA, Usman B (2013) Tuberculosis of the Female Breast and Reproductive Organs: A Diagnostic Dilemma. J Trop Dis 1: 116. doi:10.4172/2329-891X.1000116

population [33]. Diagnosis can also be achieved with Polymerase Chain Reaction (PCR) for the detection of mycobacterium DNA [38], this is however unavailable in most developing settings. Tissue microscopy showing granuloma, giant cells (langhan's or foreign body), lymphocytes and plasma cells with or without caesation is diagnostic [39]. The presence of AFB in the lesion can be confirmed with the Zeihl Neelsen stain though its presence is not necessary and AFB positivity is higher in untreated patients and HIV positive cases [24,40]. Standard anti-tuberculous drugs treatment can achieve complete resolution as in our cases and all the first line drugs of Isoniazid, Rifampicin, Ethambutol and Pyrazinamide are well tolerated in pregnancy without untoward fetal outcome $[36,37,41,42]$.

Accurate diagnosis will forestall delayed treatment, unnecessary surgeries and reduce attendant morbidity such as sterility which is common in approximately $50 \%$ of patients [8].

\section{References}

1. Dye C, Scheele S, Dolin P, Pathania V, Raviglione MC (1999) Consensus statement. Global burden of tuberculosis: estimated incidence, prevalence, and mortality by country. WHO Global Surveillance and Monitoring Project. JAMA 282: 677-686.

2. Raviglione MC, Dye C, Schmidt S, Kochi A (1997) Assessment of worldwide tuberculosis control. WHO Global Surveillance and Monitoring Project. Lancet 350: 624-629.

3. World Health Organization (2003) Global tuberculosis control: surveillance, planning and financing. Geneva: WHO.

4. World Health Organization (2005) TB cases and death linked to HIV now at alarming levels in Africa.

5. Soliman MS, Lessnau K, Hashmat A (2007) Tuberculosis of the genitourinary system.

6. Taylor Z, Nolan CM, Blumberg HM; American Thoracic Society; Centers for Disease Control and Prevention; Infectious Diseases Society of America (2005) Controlling tuberculosis in the United States. Recommendations from the American Thoracic Society, CDC, and the Infectious Diseases Society of America. MMWR Recomm Rep 54: 1-81.

7. Barnes PF, Bloch AB, Davidson PT, Snider DE Jr (1991) Tuberculosis in patients with human immunodeficiency virus infection. N Engl J Med 324: 1644-1650.

8. Hughes LE, Mansel RE, Webster DJ (1987) Aberrations of normal developmen and involution (ANDI): a new perspective on pathogenesis and nomenclature of benign breast disorders. Lancet 2: 1316-1319.

9. Raw N (1924) TUBERCULOSIS OF THE BREAST. Br Med J 1: 657-658

10. Banerjee SN, Ananthakrishnan N, Mehta RB, Parkash S (1987) Tuberculous mastitis: a continuing problem. World J Surg 11: 105-109.

11. Mehta G, Mittal A, Verma S (2010) Breast tuberculosis- clinical spectrum and management. Indian J Surg 72: 433-437.

12. Bani-Hani KE, Yaghan RJ, Matalka II, Mazahreh TS (2005) Tuberculous mastitis: a disease not to be forgotten. Int J Tuberc Lung Dis 9: 920-925.

13. De Sousa R, Patil R (2011) Breast tuberculosis or granulomatous mastitis: A diagnostic dilemma. Ann Trop Med Public Health 4: 122-125.

14. Harris SH, Khan MA, Khan R, Haque F, Syed A, et al. (2006) Mammary tuberculosis: analysis of thirty-eight patients. ANZ J Surg 76: 234-237.

15. Schaefer G (1976) Female genital tuberculosis. Clin Obstet Gynecol 19: $223-$ 239.

16. Cantwell MF, Shehab ZM, Costello AM, Sands L, Green WF, et al. (1994) Brief report: congenital tuberculosis. N Engl J Med 330: 1051-1054.

17. Mukerjee P, George M, Maheshwari HB, Rao CP (1974) Tuberculosis of the breast. J Indian Med Assoc 62: 410-412.

18. Al-Marri MR, Almosleh A, AlmosImani Y (2000) Primary tuberculosis of the breast in Qatar: ten year experience and review of the literature. Eur $\mathrm{J}$ Surg 166: 687-690.

19. Shinde SR, Chandawarkar RY, Deshmukh SP (1995) Tuberculosis of the breast masquerading as carcinoma: a study of 100 patients. World J Surg 19 : 379-381.
20. Tewari M, Shukla HS (2005) Breast tuberculosis: diagnosis, clinical features \& management. Indian J Med Res 122: 103-110.

21. Dodiyi-Manuel ST, Dodiyi-Manuel A (2013) Tuberculosis of the breast. Niger J Med 22: 72-74

22. Cooper A (1829) Illustration of the diseases of the breast. Part I. Longmans, Orme, Brown, Green. London 73.

23. McKeown KC, Wilkinson KW (1952) Tuberculosis of the breast. Br J Surg 39 420-429.

24. Martínez-Parra D, Nevado-Santos M, Meléndez-Guerrero B, García-Solano $\mathrm{J}$, Hierro-Guilmain CC, et al. (1997) Utility of fine-needle aspiration in the diagnosis of granulomatous lesions of the breast. Diagn Cytopathol 17: 108114.

25. Samaila MO, Oluwole OP (2011) Extrapulmonary tuberculosis: fine needle aspiration cytology diagnosis. Niger J Clin Pract 14: 297-299.

26. Mehrotra R (2004) Fine needle aspiration diagnosis of tuberculous mastitis. Indian J Pathol Microbiol 47: 377-380

27. Namavar Jahromi B, Parsanezhad ME, Ghane-Shirazi R (2001) Female genita tuberculosis and infertility. Int J Gynaecol Obstet 75: 269-272.

28. Bapna N, Swarankar M, Kotia N (2005) Genital tuberculosis and its consequences on subsequent fertility. J Obstet Gynecol India 55: 534- 537.

29. Shyramala Guruvare, Pralhad Kushtagi (2007) Genital Tuberculosis Manifesting As Sinus Tracts. Int J Gynaecol Obstet 7:2.

30. Aliyu MH, Aliyu SH, Salihu HM (2004) Female genital tuberculosis: a global review. Int J Fertil Womens Med 49: 123-136.

31. Morris CA, Boxall FN, Cayton HR (1970) Genital tract tuberculosis in subfertile women. J Med Microbiol 3: 85-90.

32. Tripathy SN, Tripathy SN (2002) Infertility and pregnancy outcome in female genital tuberculosis. Int J Gynaecol Obstet 76: 159-163.

33. Rao GJ, Ravi BS, Cheriparambil KM, Pachter B, Pujol F (1996) Abdominal Tuberculosis or Ovarian Carcinoma: Management Dilemma Associated With an Elevated CA-125 Level. Medscape Womens Health 1: 2.

34. Agarwal J, Gupta JK (1993) Female genital tuberculosis--a retrospective clinico-pathologic study of 501 cases. Indian J Pathol Microbiol 36: 389-397.

35. Bilgin T, Karabay A, Dolar E, Develioğlu OH (2001) Peritoneal tuberculosis with pelvic abdominal mass, ascites and elevated CA 125 mimicking advanced ovarian carcinoma: a series of 10 cases. Int J Gynecol Cancer 11: 290-294.

36. Marinopoulos S, Lourantou D, Gatzionis T, Dimitrakakis C, Papaspyrou I, et al. (2012) Breast tuberculosis: Diagnosis, management and treatment. Int J Surg Case Rep 3: 548-550.

37. Seker D, Kaya O, Seker GE (2010) Tuberculosis of the breast: medica treatment. Acta Chir Belg 110: 614-615.

38. Verma K, Kapila K (2002) Aspiration cytology for diagnosis of tuberculosisperspectives in India. Indian J Pediatr 69 Suppl 1: S39-43.

39. John Samuelson (1999) Infectious Diseases In: Cotran R.S, Kumar V, Collins $\mathrm{T}$ (eds). Robbins Pathologic Basis Of Disease. W.B Saunders Company Philadelphia 6th: 349- 352.

40. Sinha SK, Chatterjee M, Bhattacharya S, Pathak SK, Mitra RB, et al. (2003) Diagnostic evaluation of extrapulmonary tuberculosis by fine needle aspiraton (FNA) supplemented with AFB smear and culture. J Indian Med Assoc 101 588, 590-591.

41. Bothamley G (2001) Drug treatment for tuberculosis during pregnancy: safety considerations. Drug Saf 24: 553-565

42. Olabisi M Loto, Ibraheem Awowole (2012) Tuberculosis in Pregnancy: A Review. Journal of Pregnancy vol. 2012, Article ID 379271, 7. 